\title{
LAS MIGRACIONES INTERNACIONALES, NUEVAS IDENTIDADES, NUEVAS CIUDADANÍAS
}

\author{
INTERNATIONAL MIGRATIONS, NEW IDENTITIES, NEW CITIZENSHIPS
}

\author{
Jesús Labrador Fernández \\ Universidad Pontificia de Comillas, España
}

\begin{abstract}
Resumen: Las migraciones contemporáneas están interpelando directamente tanto la idea de identidad y de identidad nacional como la idea de ciudadanía.

En un mundo cada vez más acelerado y en el que interviene una mayor diversidad los procesos de construcción de la identidad son cada vez más complejos y además se hacen más comunes los procesos de adaptación y renegociación de la identidad. Las identidades estables, únicas y puras están en crisis. Por otra parte, las fronteras nacionales de los estados nación son cada vez más permeables, para el capital, la información y las personas. Los límites nacionales en otro momento tan claros hoy se diluyen, con la confusión que eso puede generar.
\end{abstract}

Palabras clave: Migración, identidad, ciudadanía.

\begin{abstract}
The contemporary migrations are directly questioning the idea of identity, national identity and the citizenship concept. In a world increasingly accelerated with a greater diversity, the processes of identity construction are more and more complex and in addition the processes of identity adaptation and renegotiation become common. Stable, unique and pure identities are in crisis. On the other hand, national borders of the nation are more permeable, for capital, information and people. The national limits at another moment so clear, today are diluted, with the confusion this situation may generate.
\end{abstract}

Key Words: Migration, identity, citizenship.

\section{INTRODUCCIÓN}

Las migraciones que estamos viviendo en estos últimos años son un fenómeno estructural, universal y fuertemente acelerado. Castells (1998) ya señalaban como primera característica de las migraciones modernas su carácter globalizado. Palabra esta que esta en boca de todos pero que en este contexto hace referencia, en primer lugar, a que hay un número cada vez mayor de países implicados, y por otra parte, a un cada vez mayor cuestionamiento de las fronteras y de los estado nación heredados de la modernidad nacionalista del XIX.

El Consejo de Europa (1992) definía a las migraciones contemporáneas como un fenómeno estructural de importancia mundial y señalaba una serie de factores explicativos de los actuales flujos migratorios internacionales, que hacen de estos un fenómeno nuevo y diferente a las migraciones de siglos pasados. Estos factores son:

- Desequilibrio de las perspectivas de desarrollo económico en el mundo.

Basta con ojear cualquier informe sobre desarrollo humano (PNUD, 2007) para comprobar como la brecha entre países ricos y pobres es cada vez mayor.

Basta con asomarse a cualquier telediario para que ese desequilibrio nos abofetee con sus imágenes a las cuales desgraciadamente nos estamos acostumbrando.

- Diferencias sensibles respecto a los derechos humanos.

No sólo se producen desequilibrios en los factores económicos. El respeto a la vida, la libertad y otros derechos humanos no son un bien universal. No es infrecuente escuchar a inmigrantes, cuando rememoran sus primeras impresiones al llegar a España, ponderar la seguridad o la libertad que sienten en su nuevo destino.

Sorprendentes discursos desde el punto de vista de los investigadores, pero que rápidamente se explican cuando se contempla la situación política y social de sus lugares de origen.

Conferencia presentada por el autor en la Facultad de Psicología de la Universidad Católica del Uruguay, en la ciudad de Montevideo el 15 de abril de 2009, como único conferencista invitado por los Departamentos de Psicología Social y Organizacional y de Psicología del Desarrollo y Educación. En el marco de las actividades de los programas de Maestría en Psicología Educacional y de Maestría en Intervención Psicopedagógica. 
- Presión demográfica. Nos encontramos con la extraña paradoja de que el Sur no tiene los medios económicos necesarios para hacerse cargo de su crecimiento demográfico, y el Norte no tiene los medios demográficos para sostener su crecimiento económico. Y las perspectivas de futuro nos dicen que el desequilibrio va a ser todavía mayor.

- Mejores y mayores posibilidades de transporte. De la misma manera que hace unos años era fácil encontrar taxistas de otras provincias en Madrid, hoy es fácil encontrar taxistas en Nueva York que son de Bangladesh o mineros en León que proceden de Cavo Verde.

\section{VIAJEROS O INMIGRANTES}

En un mundo en el que los flujos de capital, información y personas es cada vez mayor y más acelerado, es necesario precisar con la mayor certeza posible la separación entre los viajeros, que nos trasladamos con frecuencia y que atravesamos fronteras, y los emigrantes o inmigrantes que salen de sus países y llegan a otros con el interés de reconstruir su vida en ese nuevo entorno.

¿Cuáles son los elementos que definen y justifican que un desplazamiento de un individuo o grupo sea llamado migración? Troyano (1998) distingue cuatro características que deben estar presentes para poder hablar de que se produce este fenómeno.

- En primer lugar el propio desplazamiento en el espacio antes mencionado. Este recorrido geográfico tiene un valor muy relativo, por sí solo no define nada, $3.000 \mathrm{Km}$. de distancia no tienen por qué definir una emigración y en cambio 20 Km. sí.

- Deben estar presente, así mismo, una serie de variables que con mayor o menor peso caractericen de una manera u otra el movimiento migratorio.

V1. Se produce una presión expulsora explicada casi siempre por una desajustada relación entre población y recursos.

V2. Una llamada por parte de los países de recepción que exportan la idea de que la relación antes mencionada tiene también desajustes, pero en un sentido opuesto.

V3. Información que discurre con rapidez por las redes sociales que se crean, mediante lazos históricos y sociales que ya existían la mayor parte de la veces.
V4. Redes de solidaridad grupal que facilitan el tránsito y el asentamiento.

- En cuanto a la persona que acomete el esfuerzo migratorio, siempre está presente en ella una clara motivación: mejorar sus condiciones de vida. Este concepto es tan relativo como el anterior de desplazamiento, cada persona lo definirá según un complejo juego de variables internas y externas. A este respecto hay que decir que hemos encontrado diferencias que están presente en toda la trayectoria migratoria, cuando el motivación de partir es intrínseca que cuando el individuo se ve arrastrado por una serie de circunstancias y situaciones sociopolíticas que hacen que la persona caezca de control sobre sus propias decisiones (Labrador, 2001, 2007)

- Por último, y desgraciadamente muy habitual, se produce un rechazo de la población receptora explicado mediante discursos que tienen que ver con la competencia por recursos escasos y el desvanecimiento del espejismo de la homogeneidad cultural del país de origen.

España, al ir incorporándose al selecto grupo de los países del Norte desarrollado comenzó a ser el destino de gentes con una evidente motivación de trabajo y asentamiento. Algunas de esas personas ocuparon lugares de estatus elevado: rentistas de la Unión Europea, profesionales transeúntes generados por las inversiones de empresas multinacionales, y profesionales formados en países periféricos que protagonizan una fuga de cerebros desde sus países a los nuestros (Colectivo loé, 2001). Otros ocuparon y siguen ocupando estatus desfavorecidos, son las gentes que vienen de esos países pobres que no pueden hacerse cargo de su crecimiento demográfico. Sin embargo, el origen, los países del denominado Sur, no es lo que les identifica como inmigrantes, ni la motivación de asentamiento, ni los trabajos que desempeñan. El elemento necesario, no suficiente pero si crítico, que establece la categoría de inmigrante diferenciándolo del resto de extranjeros, es el rechazo que generan por parte de la población aborigen.

Como vemos en el siguiente gráfico, este crecimiento de población extranjera en mi país ha sido en la última década muy notorio, y si un simple vistazo a las estadísticas nos hace evidente ese crecimiento, un breve paseo por muchas de nuestras ciudades nos proporciona múltiples señales de esta importante transformación que estamos viviendo. 


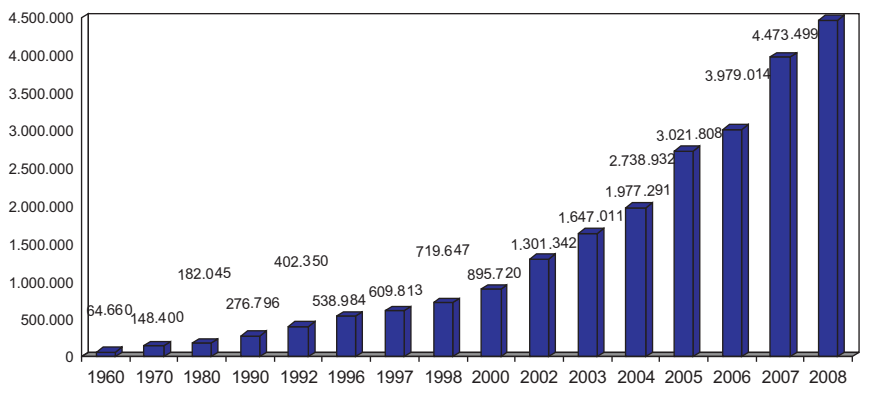

Grafico I. Ciudadanos extranjeros con certificado de registro o tarjeta de residencia. Fuente: Ministerio de Trabajo e inmigración (dic 2008). Elaboración propia.

El encuentro entre la comunidad de destino, los aborígenes, y el inmigrante se produce habitualmente en dos frentes que están profundamente interrelacionados. Por un lado se produce el encuentro con la migración como fenómeno cotidianamente visible en las ciudades y determinadas zonas de nuestro país. Este encuentro es evidenciado reiteradamente en los medios de comunicación al que le suelen atribuir el significado de grave problema social. Problema que está caracterizado casi siempre desde la idea del conflicto y la inseguridad y casi nunca desde la idea de la oportunidad. Hay que decir que también es fácil escuchar un discurso en el que se reconoce el inestimable aporte que ha tenido toda esta población en el desarrollo económico que ha experimentado España.

Por otro lado se produce el encuentro con el inmigrante. Este ya es un encuentro personal en el que suele estar presente el desconcierto y el miedo que tiende a invisibilizar y a crear una barrera entre ellos y nosotros.

Este encuentro entre la población inmigrante y la aborigen ha ido configurando a lo largo de todos estos años una serie de prácticas de interacción social que están presididas por el cambio y el conflicto.

Los retos y las transformaciones que plantea la población inmigrante a nuestro país y a todo el occidente desarrollado son, posiblemente, los más colosales y difíciles que se han tenido que afrontar desde la reconstrucción de Europa al término de las guerras mundiales.
Es necesario, así mismo, hacer otra consideración preliminar. La evolución de los flujos de inmigrantes hacia nuestro país no ha dejado de incrementarse desde mediados de los ochenta. Este incremento no es uniforme en todo el estado, la población extranjera se asienta allí donde las posibilidades de trabajar son mayores lo cual hace que existan zonas en nuestro país, ya sea por la presencia de producciones agrícolas o por la de servicios sin cualificar, en los que la población extranjera es ya muy significativa.

Sin embargo el número no es el único factor relevante del fenómeno migratorio en mi país, la gran diversidad de los orígenes y culturas así como de situaciones personales, preparación profesional y estatus socioeconómico incrementa de forma exponencial la complejidad de nuestra sociedad y por tanto de la convivencia de sus ciudadanos.

Vemos como entre los cuatro primeros países de origen de la migración en España están representados cuatro continentes distintos, que nos llevan a formas muy distintas de entender el mundo, la vida, a los otros, la transcenciencia... Complejidad a la que también contribuimos los españoles con su diversidad y sus distintas formas de establecer las relaciones intergrupales.

Quizá esta es la idea básica que pretendo transmitirles, los intercambios e interacciones de información y de personas que caracterizan este mundo globalizado sumergen al individuo en un ambiente en el que crecer y construirse es también más complejo.

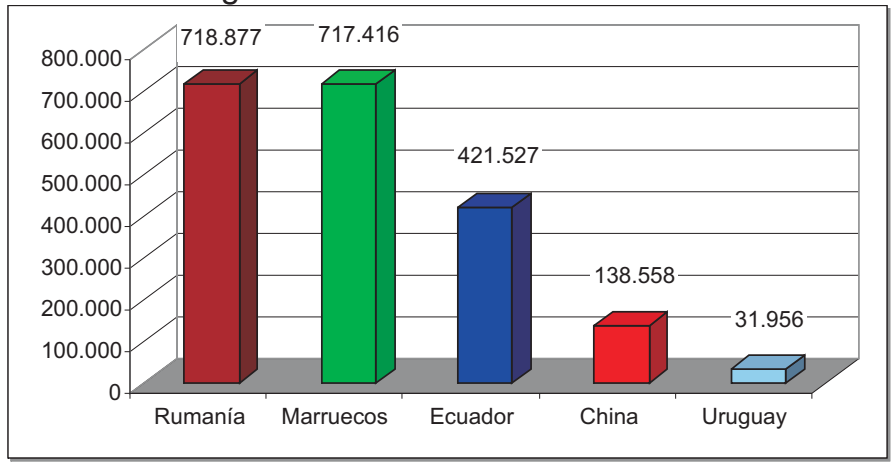

Gráfico 2. Ciudadanos con certificado de registro o tarjeta de residencia de los países de origen más significativos en la inmigración en España. Fuente: Ministerio de Trabajo e inmigración (dic 2008). Elaboración propia. 
Las categorías simples: el si o el no, el blanco o el negro, el 1 o el 0 son formas de categorizar cada vez menos adaptadas a la realidad. En esa diversa complejidad las personas debemos configurar y construir nuestra identidad, vamos a hacer una pequeña digresión hacia la psicología del desarrollo para evidenciar algunos de los elementos más sensibles en ese proceso de crecimiento que genera seres humanos con una identidad, o quizás haya que decir, con múltiples identidades.

\section{LASBASESDELDESARROLLODELAIDENTIDAD. IDENTIDAD Y PERTENENCIA}

La familia y las figuras de apego son los primeros agentes de medición para la construcción de la identidad. Esta transcendente construcción se va a ir realizando por medio del lenguaje en la interacción humana. A esos primeros agentes les debemos, al menos, nuestra identidad como humanos, como varones o mujeres y como miembros de una determinada estirpe o grupo familiar. Estas tres pertenencias son las más básicas y fundantes de lo que luego será un individuo, también son tres pertenencias muy flexibles o, por decirlo de otra manera, son muchas las posibilidades de realización concreta en las personas y en sus prácticas. Son también el más primario ejemplo de eso que hoy vamos a llamar multipertenencia. Cada uno de nosotros pertenecemos a esos tres grupos y cada uno de nosotros lo hace de una forma particular e idiosincrásica.

Los individuos de nuestra especie in-corporamos esas tres identidades fundamentales de una manera casi automática, inconsciente y con bastante rapidez, sobre todo si nos referimos a los elementos más básicos y fundamentales. Y es ahí, en esos primeros años de vida, cuando comienza la lógica de la inclusión y de la exclusión.

El primero de los grupos de referencia es esencialmente inclusivo, todos somos seres humanos aunque sobran ejemplos en la historia y en el presente de seres humanos que, por una u otra circunstancia, no han gozado ni gozan de los derechos y deberes de pertenecer a la humanidad.Cuando un ser humano nace necesita mirarse en el espejo de sus iguales, sólo así ira imitando, aprendiendo e identificándose como humano.

Sin embargo es en los otros dos grupos de pertenencia donde la lógica de la inclusión y de la exclusión opera de forma más evidente. Veamos con un poco más de detenimiento esta característica un tanto paradójica de la identidad que a la vez incluye y excluye.

Cuando nos acercamos a los significados del término identidad el primero que aparece es "calidad de lo idéntico". Se nos remite a la idea de igualdad. Un sujeto o grupo es idéntico a otro, o puede identificarse con él, cuando ambos comparten cualidades más o menos esenciales que son intercambiables en uno o más aspectos. De esta forma se establecen relaciones de igualdad y similitud entre los objetos que nos sirven para contextualizarlos dentro del entorno en el que se encuentran.

Toda igualdad nos introduce necesariamente en el concepto de la diferencia. Si se establece una relación de similitud es porque existe también la de diferencia. Cuando se produce una relación de identidad, al mismo tiempo se genera una separación o diferenciación de todo aquello a lo que no es posible identificarse. Por tanto, la identidad separa, diferencia los objetos que son iguales de los que no lo son: los varones de las mujeres, los Fernández de los Arsuaga o los Worchel.

Los aspectos que consiguen que podamos distinguir a unos miembros de un grupo de los miembros del otro son esenciales. Son las marcas que todos buscamos en la interacción social, para ordenarla y darla un significado.

La relación que se establece entre los sujetos es de diferenciación sobre todo cuando la interacción se establece con "el otro". En esos casos la forma de su cuerpo, su acento o su idioma son algunas de esas marcas que sirven para calificar la interacción.

También es una relación contextualizadora que sirve para ordenar y clasificar a los otros dentro de su entorno ahora por medio de relaciones diferenciadoras.

Igualdad y diferencia son conceptos que están íntima y lógicamente relacionados: lo que hace que un individuo sea similar a otros, le distingue de los que no son esos; por lo tanto una de las características que tenemos en común con el grupo de iguales es lo que nos diferencia de los demás grupos. Así pues, cuando se habla de la identidad de un sujeto o de un grupo se hacen presentes estas relaciones de igualdad y diferencia.

Similitud y diferencia son las dinámicas principales de la identidad y la identificación (verbo y sustantivo que comparten la polisemia que 
nos concierne). Según Jenkins (1996), son el corazón de la vida social. Cuando un individuo o colectivo se identifica o es identificado tiene lugar una acción inicial de establecer relaciones sistemáticas de similitud o diferencia entre individuos, entre colectivos o entre individuos y colectivos. Es totalmente imposible imaginarse la vida social sin tener algún conocimiento de quiénes son los otros y quiénes somos nosotros. Este conocimiento se hace sobre la base del establecimiento de relaciones de similitud y diferencia.

Desde la perspectiva del desarrollo infantil y teniendo en cuenta las capacidades cognitivas del niño son imprescindibles unos límites claros entre los grupos así como unos criterios muy sencillos y evidentes de pertenencia o no pertenencia.

En esas tres primeras pertenencias señaladas los niños buscan fronteras claras e impermeables que les ayuden a diferenciar, discriminar o poner orden en el mundo en el que están comenzando a vivir. Del mismo modo que cuando aprendimos a escribir necesitábamos papel pautado o cuadriculado para poder acometer esa tarea con cierto éxito, también se necesitan en esos primeros años, fronteras lo más claras e impermeables posibles que actúen de cuadrícula o rejilla para hacerse cargo de la realidad social.

El problema radica en que, si bien durante los primeros años es necesaria esa discriminación perceptiva, también es cierto que en muchos casos los agentes de socialización: familia, escuela y medios de comunicación, exageran y perpetúan esa lógica de la exclusión. Y lo que es peor, las diferencias, amplificadas e instrumentalizadas para justificar privilegios, son transformadas en desigualdades. Desigualdades de las que es difícil salir al ser establecidas como disyunciones exclusivas ${ }^{1}$.

Son muchos los expertos en educación que han llamado la atención sobre el fenómeno de hacer de toda diferencia un juego de contrarios lo cual no sólo es un gran error lógico sino un tremendo caldo de cultivo para los enfrentamientos y las justificaciones de las desigualdades.

Es necesario comenzar a decir que todos nosotros somos varones o mujeres además de muchas otras cosas y que en esa disyunción

1En el diccionario de Ferrater Mora se distinguen dos tipos de disyunciones lógicas que además se corresponden a dos tipos de formulación gramatical en nuestro idioma. "Una de las conectivas es 'o' simbolizada por ' $V$ 'llamada disyunción inclusiva; otra es 'o...o'simbolizada por ‘ $\leftrightarrow$ 'llamada disyunción exclusiva” no debemos pensar que la mujer es lo contrario al varón. No hay en la naturaleza nada más parecido a lo uno que lo otro.

El juego de identidades es siempre múltiple y lleno de complejidad, podemos aceptar que en un principio necesitemos simplificar esa multipertenencia y esa complejidad, pero no hay por qué seguir haciéndolo después de los cinco o seis años.

Adquirimos nuestra identidad construyéndonos como individuos que confían en sus capacidades, que realizan tareas de forma autónoma y que tienen iniciativas propias.

Confianza, autonomía e iniciativa son los tres pilares sobre los que se sustenta nuestra identidad y, curiosamente según la psicología evolutiva, se construyen en esos primeros cinco o seis años.

La confianza en los otros (figuras de apego) acaba revirtiendo en confianza en nosotros mismos, en nuestra autonomía para hacer las cosas y en nuestra voluntad para tener iniciativas propias. El 'ser' de la confianza en uno mismo, el 'hacer' de nuestra autonomía y el 'querer' de nuestra iniciativa, tres infinitivos esenciales para vivir como humanos.

La portentosa capacidad de los bebés de imitar y de aprender gracias a esa imitación, nos da entrada en la categoría de humanos.

La época de tozudez por la que todos los niños pasan en la que dicen continuamente ¡NO! y ¡YO SOLO! no es más que el primer síntoma de que el proceso de ir organizando la propia identidad poniendo en práctica lo aprendido, está en marcha. La identidad diferenciadora e individualizada ya está en camino y, por supuesto, está organizándose en múltiples pertenencias.

Por otra parte cuando ese proceso esta definido desde la desconfianza, desde la falta de autonomía y la falta de independencia, es decir cuando la persona se siente insegura, es cuando se va haciendo más y más necesaria la pertenencia a grupos de forma exclusiva y excluyente. Este es un juego evidenciado por los autores clásicos de la psicología social, en el que la pertenencia a un grupo se constituye como un valor crítico para la autoestima del sujeto. Lo que no se ha podido depositar en el individuo, lo que está construido con malos materiales, es necesario apuntalarlo y sostenerlo desde las identidades grupales, colectivas y nacionales. 
Para que estas identidades den protección y aporten al individuo una buena imagen de sí mismo, es necesario que sean mejores que las de otros, el juego de la exclusión y el ataque al exogrupo está servido.

He descrito un juego más bien psicológico, pero existen situaciones sociales en las que esta hipertrofia de las identidades grupales se generaliza. Me refiero a las situaciones en que hay conflicto entre naciones o comunidades. Los sujetos que nacen en el seno de esos conflictos van a depositar en su pertenencia grupal toda una serie de emociones que hacen del juego de la inclusión y la exclusión el más importante de su existencia. En este juego perverso es necesario hacer de estas pertenencias algo puro, límpido e inmaculado. Los valores del endogrupo deben ser nítidamente expuestos y deben proporcionar una homogeneidad total a ese grupo.

Similitud y diferencia convertida en competición y exclusión han sido el corazón de la vida social sobre todo de la parte más oscura y sangrienta de nuestra historia

En cambio lo que proponen autores como Amin Maalouf (y que hago mía) es que las identidades son múltiples, llenas de contaminaciones e impurezas, fruto de un devenir histórico tremendamente mezclado y mestizo. Así, España es un país en el que la tradición principal es la católica, pero eso no nos debe impedir ver que existen también una dimensión judía, una dimensión musulmana y así mismo una dimensión anticlerical. Cada una de estas dimensiones ha desempeñado y sigue desempeñando un papel significativo en la vida del país y en la percepción profunda de la identidad.

Del mismo modo me atrevo a decir que Uruguay no se puede explicar sin un sinnúmero de dimensiones culturales que han ido gestando a lo largo de la historia de este país la identidad uruguaya.

El resultado de esta multipertenencia no debe ser medio argentino y medio español, o en el caso del autor antes citado medio francés y medio libanés. No es un juego aritmético de porcentajes en la sangre, sino que es una unidad cuántica se es lo uno y lo otro, siempre y de forma consistente.

Solo desde la conciencia de nuestra multipertenencia podremos acceder al encuentro con el otro distinto sin los miedos y recelos habituales.
Ese es el primer reto de la convivencia en la diversidad, el tomar conciencia de la propia diversidad, de la gran diversidad del endogrupo que al menos es tanta como la que existe entre el endogrupo y el exogrupo.

\section{LAS MÚLTIPLES PERTENENCIAS Y LA CIUDADANIAA}

Según la OIT el número países implicados en procesos migratorios ya sea como emisores o como receptores creció en las últimas décadas del sigo XX más de un 85\% (Stalker, 2000). Esta circunstancia por si sola nos hace sospechar que estamos ante un fenómeno cada vez más diverso, no sólo en cuanto a lenguas, culturas y etnias implicadas, sino también en lo que se refiere a que no estamos ante un tipo de flujo único ni preponderante, hay refugiados, mano de obra barata, directivos, estudiantes, etc. etc.

Las posibilidades que proporcionan al ser humano contemporáneo los medios de comunicación y de información modernos acentúan esa globalización, incrementan la diversidad, aceleran los flujos de una forma evidente $y$, sobre todo, hacen posible en la mente de las personas la idea de migrar.

Al aumentar la complejidad las identidades grupales y nacionales pasan a ser un elemento crítico en la interacción social, esto hace que en muchos caso aumente la inseguridad y los miedos personales haciendo que las personas se defiendan refugiándose en la templada atmósfera de la homogenidad y la pureza de los valores tradicionales.

Por otra, parte estas condiciones de la migración actual, en las que los flujos implicados son cada vez más diversos complejos y acelerados, están poniendo en entredicho el concepto mismo de estado nación.

Las fronteras entre los países se comienzan a diluir, y esto se puede decir al contemplar como en los mapas cognitivos de las personas inmigrantes esas fronteras por muy impermeables que se pretendan construir se conciben como un obstáculo que debe ser salvado. En muchos casos esa dificultad de la frontera no hace más que afirmar el atractivo del país que delimita y, por tanto, la necesidad de atravesarla.

De la misma forma que las fronteras cuentan cada vez menos en los sistemas económicos dominados por flujos financieros internacionales y por compañías multinacionales, también los flujos de personas y las redes familiares y de apoyo adquieren esta característica de transnacionalidad. 
Estamos ante un "proceso social en el cual los migrantes establecen campos sociales que cruzan fronteras geográficas, culturales y políticas. Los inmigrantes se consideran transmigrantes cuando desarrollan y mantienen relaciones múltiples (familiares, económicas, sociales, organizacionales, religiosas y políticas) que pasan por encima de las fronteras. Los transmigrantes realizan acciones, toman decisiones y desarrollan identidades dentro de redes que los conectan con dos o más sociedades simultáneamente" (Schiller, Basch y Blanc-Szanton, 1992: 1)

Los flujos migratorios modernos tienen, como casi todos a lo largo de la historia, una clara vocación de asentamiento permanente, aunque las pertenencias múltiples y flexibles son ahora mucho más sencillas y quizás estemos ante el umbral de una población en constante trashumancia. Pero todavía hoy las redes transnacionales se crean y las familias se reagrupan con el fin de cerrar el proyecto migratorio, proceso este largo y que, por muchas dificultades que haya en el camino, se acaba produciendo en la mayor parte de los casos.

En esta situación es común observar en los países receptores de población extranjera una doble forma de segregación definida en función de los criterios de integración y de ciudadanía. Así nos encontramos en España a ciudadanos integrados, ciudadanos no integrados, no ciudadanos integrados y no ciudadanos no integrados. Esta curiosa estratificación tiene el evidente peligro de que se puede ir produciendo una institucionalización y reforzamiento de la exclusión de los inmigrantes.
La respuesta tradicional que se está dando desde los estados actuales a esta situación es la de proporcionar una larga carrera al inmigrante en la que se van salvando una serie de obstáculos: la frontera, el mercado laboral, la vivienda, la cultura y, por último, la identidad nacional. Sólo la superación de este obstáculo final asegura los los plenos derechos, entre los que encontramos los políticos.

En las naciones occidentales comienzan a asentarse cada vez más ciudadanos de otros países con otras pertenencias que son al mismo tiempo más flexibles y sobre todo múltiples.

El caso de los inmigrantes es particularmente difícil al tener que gestionar esa multiplicidad y esa flexibilidad cuando uno de los componentes principales es el rechazo.

Esta es la lógica excluyente del los estados-nación que se están enfrentando ahora a un número cada vez mayor de individuos que superan todos esos obstáculos y que ante la naturalización, bien por decisión propia, bien por políticas muy restrictivas del derecho a la nacionalidad, no lo superan.

La presencia cada vez mayor de no ciudadanos asentados, con residencia permanente en nuestra nación, que contribuyen con su esfuerzo y sus impuestos al mantenimiento de esa misma nación que no les da todos los derechos es cada vez más numerosa y entraña una paradoja insostenible.

No es extraño que vuelva a la memoria de algunos expertos el viejo grito de la independencia americana: no taxation without representation.

MODELOS DE CIUDADANÍA

\begin{tabular}{|c|c|c|c|}
\hline & Tradicional & Transnacional & Postnacional \\
\hline $\begin{array}{l}\text { supuestos } \\
\text { teóricos }\end{array}$ & $\begin{array}{l}\text { Cada individuo es un } \\
\text { ciudadano con una } \\
\text { nacionalidad que vinculan a } \\
\text { ese sujeto con un estado } \\
\text { nación. }\end{array}$ & $\begin{array}{l}\text { Los inmigrantes o "viajeros" } \\
\text { que viven cruzando fronteras y } \\
\text { creando actividades } \\
\text { transnacionales, también crean } \\
\text { identidades transnacionales. } \\
\text { La ciudadania y la nacionalidad } \\
\text { pueden ser múltiple y la } \\
\text { pertenencia es a estados nación } \\
\text { "desterritorializados". }\end{array}$ & $\begin{array}{l}\text { Es un cambio de radical } \\
\text { de reglas donde se prima } \\
\text { lo individual y lo personal. } \\
\text { Los derechos no dependen } \\
\text { de la ciudadanía. } \\
\text { La identidad transciende } \\
\text { al estado nación }\end{array}$ \\
\hline implicaciones & $\begin{array}{l}\text { El inmigrante puede } \\
\text { nacionalizarse. } \\
\text { A la larga, aunque se } \\
\text { disponga de dos } \\
\text { nacionalidades, sólo será } \\
\text { relevante la del país de } \\
\text { acogida Integración } \\
\text { dificultosa y conflictiva del } \\
\text { extraño, del que no tiene } \\
\text { raíces. }\end{array}$ & $\begin{array}{l}\text { Un número significativo de } \\
\text { inmigrantes tendrán } \\
\text { ciudadanias y nacionalidades } \\
\text { duales o múltiples. } \\
\text { El número de individuos con } \\
\text { múltiple ciudadanía crecerá } \\
\text { Los marginados (originarios de } \\
\text { países pobres) pueden tener dos } \\
\text { fuentes de identificación. }\end{array}$ & $\begin{array}{l}\text { La importancia de la } \\
\text { nacionalidad sea una o } \\
\text { múltiple irá descendiendo } \\
\text { tanto en cuanto los } \\
\text { derechos humanos vayan } \\
\text { configurándose como } \\
\text { norma universal Los } \\
\text { derechos humanos se } \\
\text { constituyen como fiel de } \\
\text { todas las relaciones }\end{array}$ \\
\hline
\end{tabular}

Fuente: Bloemraad, I. (2004) 
Tres alternativas políticas empiezan a vislumbrarse en el panorama teórico que intentan hacerse cargo de esta situación contradictoria.

Por un lado estaría la postura tradicional en la que se propone la naturalización de los inmigrantes mediante un proceso de asimilación, dicho en otras palabras: "o se hacen como nosotros, o se que callen, o que se marchen".

Lo que si puede revisarse son las dificultades y los plazos para llegar a esa naturalización asimiladora, pero la lógica sigue siendo la misma: la radical separación entre nosotros y ellos.

Otras voces proponen la sustitución de la nacionalidad por el empadronamiento y la residencia permanente como formula para adquirir plenos derechos (Zapata-Barrero, 2000).

También surgen otras voces en las que se apela a referentes superiores como es la declaración universal de los derechos humanos en el que los principios de igualdad y seguridad jurídica transcienden la lotería genética y nacional (Colectivo loé, De Lucas, 2002).

Bloemraad, (2002) propone el siguiente cuadro resumen que de alguna manera ayuda a comprender la curiosa encrucijada histórica en la que nos encontramos.

No me atrevo a decir cual será el futuro de estas adscripciones nacionales de tan enorme importancia para el desarrollo de la vida social. Lo más probable es que sea una que ni se nos ha ocurrido. En cualquier caso otro mundo y otra ordenación de él es, no sólo necesaria, sino imprescindible.

\section{REFERENCIAS}

Bloemraad, I. (2004). Who claims dual citizanship? The limits of postnationalism, the possibilities of transnationalism, and the persistence of traditional citizenship. International migration review. Vol 38 № 2: 389-426

Castells, M. (1998). La era de la información. Economía sociedad y cultura. Vol 2 El poder de la identidad. Madrid: Alianza

Colectivo loé. (1999). Inmigrantes, trabajadores, ciudadanos. Valencia: Universidad de Valencia.
Colectivo loé. (2001). Flujos migratorios internacionales. Marco de comprensión y características actuales. Migraciones $N^{\circ}$ 9. pp. 7-43

Colectivo IOE (2002). "Migraciones internacionales: entre el capitalismo global y la jerarquización de los Estados", Claudia Clavijo y Mariano Aguirre (Eds.). Políticas sociales y Estado de bienestar en España: Las migraciones, Informe 2002, Madrid, FUHEM.

Consejo de Europa (1992). De l'Oural vers l'Atlantique: la nouvelle donne migratoire. Estrasburgo: Les éditions du Conseil de l'Europe.

De Lucas, J. (2002). Integración, inmigración, derechos humanos, en Rubio M.J. y Monteros, S. (Cords.). La exclusión social. Teoría y práctica de la intervención. Madrid: CCS, pp. 69-98.

Jenkins, R. (1996). Social Identity. London: Routledge.

Labrador, J. (2001). Identidad e inmigración. Madrid: Universidad P. Comillas.

Labrador, J. y Blanco, M.R. (2007). Nadie debe perder. Hijos de inmigrantes en su camino hacia la vida adulta. Madrid: Universidad P. Comillas.

Maalouf, A. (1999). Identidades asesinas. Madrid: Alianza Editorial.

Ministerio de Trabajo e Inmigración. Anuario Estadístico de Emigración 2006.

Online,13-10-08. http://extranjeros.mtin.es/es/InformacionEstadistica/Anuarios/Anuario2008.html.

Programa de las Naciones Unidas para el Desarrollo. Informe anual 2007.

Stalker, P. (2000). Workers without frontiers: the impact of globalization on international migration. Geneva: Lynne Rienner Publishers. International Labour Office.

Schiller, N., Basch, L. y Blanc-Szanton, C. (1992). Towards a transnational perspective on migrantion. The New York Academy of Sciences, 645.

Zapata-Barrero, R. (2000). Política de inmigración y Unión Europea. Claves de la razón práctica. No 104, pp.2632. 